\title{
Gold nanoparticle mediated combined cancer therapy
}

\author{
Celina Yang ${ }^{1}$, Kyle Bromma², Caterina Di Ciano-Oliveira ${ }^{3}$, Gaetano Zafarana ${ }^{4}$, Monique van Prooijen ${ }^{5}$ \\ and Devika B. Chithrani ${ }^{1,2,3^{*}}$ (1)
}

\author{
*Correspondence: \\ devikac@uvic.ca \\ 2 Department of Physics \\ and Astronomy, University \\ of Victoria, 3800 Finnerty \\ Road, Victoria M5B 1W8, \\ Canada \\ Full list of author information \\ is available at the end of the \\ article
}

\section{Abstract}

Background: The combined use of radiation therapy and chemotherapy is commonly being used in cancer treatment. The side effects of the treatment can be further minimized through targeted delivery of anticancer drugs and local enhancement of the radiation dose. Gold nanoparticles (GNPs) can play a significant role in this regard since GNPs can be used as radiation dose enhancers and anticancer drug carriers. Anticancer drug, bleomycin, was chosen as the model drug, since it could be easily conjugated onto GNPs through the gold-thiol bond.

Methods: Gold nanoparticles of size $10 \mathrm{~nm}$ were synthesized using the citrate reduction method. The surface of The GNPs was modified with a peptide sequence (CKKKKKKGGRGDMFG) containing the RGD domain and anticancer drug, bleomycin. Human breast cancer cells (MDA-MB-231) were incubated with $0.3 \mathrm{nM}$ concentration of GNPdrug complex for $16 \mathrm{~h}$ prior to irradiation with a $2 \mathrm{~Gy}$ single fraction of $6 \mathrm{MV} \mathrm{X}$-rays. After the treatment, cells were trypsinized and seeded in $60 \mathrm{~mm}$ dishes for clonogenic assay. Damage to DNA was probed using immunofluorescence assay.

Results: Cancer cells internalized with the GNP-drug complex had a $32 \pm 9 \%$ decrease in cell survival and statistically significant enhancement in DNA (deoxyribonucleic acid) damage as compared to control cells (irradiated with no GNPs) after receiving a radiation dose of $2 \mathrm{~Gy}$ with $6 \mathrm{MV}$ photons.

Conclusions: The experimental results demonstrate that GNP-mediated chemoradiation has the potential to improve cancer care in the near future through enhancement of the local radiation dose and controlled delivery of anticancer drugs.

Keywords: Gold nanoparticles, Drug delivery, Radiation dose enhancer, Combined therapy, DNA damage
\end{abstract}

\section{Background}

Cancer is one of the leading causes of death in the worldwide and patients diagnosed with cancer are expected to reach 22 million in the next two decades (Stewart and Wild 2014). The main therapeutic modalities for cancer treatment other than surgery are chemotherapy and radiation therapy. In radiation therapy, energy is deposited in the target area, damaging the cancer cells or their vasculature inducing tumor death or blockage of nutrients (Hainfeld et al. 2006). In chemotherapy, cytotoxic chemotherapeutic drugs are administered to cause cancer cell death through various mechanisms

(c) The Author(s) 2018. This article is distributed under the terms of the Creative Commons Attribution 4.0 International License (http://creativecommons.org/licenses/by/4.0/), which permits unrestricted use, distribution, and reproduction in any medium, provided you give appropriate credit to the original author(s) and the source, provide a link to the Creative Commons license, and indicate if changes were made. 
depending on the particular drug used (Crawford 2013). The combined use of radiation therapy and chemotherapy is being used in cancer treatment. Despite successful clinical application of combined radiation therapy and chemotherapy, the major limitation of combining chemotherapy and radiation therapy is the normal-tissue toxicity, since either modality can cause major normal-tissue toxicity (Herscher et al. 1999; Ma et al. 2003). Side effects of the treatment can be further minimized through targeted delivery of anticancer drugs and local enhancement of the radiation dose. Gold nanoparticles (GNPs) can play a significant role in this regard, since GNPs can be used as radiation dose enhancers and anticancer drug carriers (Yohan and Chithrani 2014; Yang et al. 2016; Chithrani et al. 2010).

The use of high- $Z$ elements to improve radiation therapy outcomes has greatly increased in the last decade, with an interest in GNPs. Early work by Hainfeld et al. 2004 showed GNPs as radio sensitizers by demonstrating natural tumor specificity and substantial improvements in tumor control in mice receiving kilo voltage radiotherapy minutes after intravenous injection of GNPs. Previous experimental studies showed that GNPs enhance radiation doses in both the $\mathrm{kV}$ and MV range in vitro and in vivo (Chithrani et al. 2010; Hainfeld et al. 2004; Jain et al. 2011). However, greater radiation sensitization was seen for cells irradiated with lower energy beams $(\mathrm{kV})$ than with higher energy beams (MV) (Chithrani et al. 2010; Rahman et al. 2009). However, megavoltage energy photons are generally used in radiation therapy, since they can reach tumors located deep within the patient. Hence, in this study, clinically relevant $6 \mathrm{MV}$ energy photons were used for radiation experiments.

GNPs can also be used as an anticancer drug carrier (Ma et al. 2003; Jain et al. 2011). Bleomycin (BLM) has been chosen as the anticancer drug for this study. Bleomycin (BLM), used in this study, is one of the most potent natural anti-tumor drugs and has been used for chemotherapeutic agents in clinical treatments (Umezawa et al. 1980; Hecht 1986). The therapeutic effectiveness, however, is limited due to the side effects of the drug, most notably pulmonary toxicity (Georgelin et al. 2010). Bleomycin binds to the DNA and causes unwinding of the double helix and generates reactive oxygen radical species that causes DNA strand breaks (Siu and Malcolm 2005). The sulfate ending of bleomycin attaches onto the surface of GNPs and this simple conjugation makes it an ideal drug to use in a combinational study experiment. The authors believe that NPbased platform discussed in this study could be used in the future for efficient and controlled delivery within the target.

The use of GNPs as radiation dose enhancers and anticancer drug carriers has shown promising results as discussed before. The next logical step was to test whether GNPs can provide significant improvement in combined chemoradiation. In this study, the GNP-mediated chemoradiation was tested for the first time with a clinically relevant radiation source of energy $6 \mathrm{MV}$ using an in vitro breast cancer cell model. MDAMB-231 cells were used, since it has been investigated in previous gold nanoparticle (GNP) studies (Jain et al. 2011; Cui et al. 2014; Butterworth et al. 2010; Wang et al. 2015; Jain et al. 2014). This cell line has been observed to have relatively good GNP uptake and significant radiosensitization (McMahon et al. 2011). For example, Jain et al. observed that the MDA-MB-231 cells had greatest uptake of GNPs among the type of cells (normal lung L132, prostate cancer DU145, breast cancer MDA-MB-231) used in uptake 
studies (Jain et al. 2011). MDA-MB-231 cells are also a triple negative cell line that are known to be more aggressive, highly invasive with worse prognosis (Dai et al. 2017), therefore selected to study new options to further improve the currently used treatment modalities. In addition, MDA-MB-231 cells express high levels of integrins, including av $\beta 3$ receptors (Vloedgraven et al. 1997) and are targeted by integrin-binding proteins that will be used to modify the surface of GNPs in this study.

It is also important to consider the size of the GNP platform, since they range from 1 to $100 \mathrm{~nm}$. Smaller GNPs have a better penetration within tumor matrix, although the highest uptake at the cellular level was found to be for GNPs of diameter $50 \mathrm{~nm}$ (Chithrani et al. 2006; Yohan et al. 2015; Gao et al. 2005). There have been efforts made to enhance the uptake of smaller NPs. One of the approaches is to conjugate NPs with a peptide sequence containing integrin-binding domain, RGD (Yang et al. 2014). GNPs of diameter $10 \mathrm{~nm}$ was selected for this study, since their potential in a real tumor like environment is greater (Perrault et al. 2009).

\section{Methods}

\section{Synthesis and surface modification of gold nanoparticles}

Gold NPs of size $10 \mathrm{~nm}$ were synthesized using the citrate reduction method (Frens 1973; Hermanson 1996). GNPs were first stabilized with penta-peptide (300 peptides/ GNP). The sequence of the penta-peptide is Cys-Ala-Leu-Asn-Asn-OH (CALNN) (AnaSpec, San Jose, USA). The peptide with RGD domain was added to the CALNN stabilized GNPs with a ratio of 16-20 peptide/GNP. The sequence of the peptide containing integrin-binding domain, RGD, is H-Cys-Lys-Lys-Lys-Lys-Lys-Lys-Gly-Gly-ArgGly-Asp-Met-Phe-Gly-OH (CKKKKKKGGRGDMFG) sequence (AnaSpec, San Jose, USA). This RGD peptide modified GNP construct will be labeled and referred to as GNP-RGD. Bleomycin (BioShop) was added onto GNP-RGD with a ratio of approximately 780 bleomycin molecules/GNP. Conjugation of bleomycin molecules onto the GNP surface occurs though a gold-thiol bond. This construct will be labeled and referred to as GNP-RGD-BLM.

\section{Cell culture and particle delivery}

Human breast cancer cell line, MDA-MB-231, was used for this study. The cells were cultured in Dulbecco's Modified Eagle's Medium (DMEM) supplemented with 10\% Fetal Bovine Serum (FBS) at $37{ }^{\circ} \mathrm{C}$ humidified incubator with $5 \% \mathrm{CO}_{2}$. For optical imaging purposes, the cells were placed on glass coverslips, grown to $75-80 \%$ confluency, and then incubated with GNP complexes $(0.3 \mathrm{nM})$ for $16 \mathrm{~h}$. Following the incubation, the coverslips were washed three times with phosphate-buffered saline (PBS). Subsequently, the cells were fixed with $4 \%$ paraformaldehyde in PBS for $20 \mathrm{~min}$ at room temperature and then mounted onto glass slides.

\section{Quantification of GNP uptake in cells}

GNP uptake in cells was quantified using inductively coupled plasma atomic emission spectroscopy (ICP-AES) (Yohan and Chithrani 2014). After incubation with GNPs, the cells were washed three times with PBS and were counted for quantification. Cells were processed with aqua regia in a silica oil bath for $2 \mathrm{~h}$. Samples were diluted and 
concentrations of gold $(\mathrm{Au})$ atoms were measured in $\mathrm{mg} / \mathrm{L}$ with the Optima $7300 \mathrm{DV}$ ICP-AES (Perkin Elmer, Waltham, USA).

\section{Clonogenic assay}

The cells were trypsinized and seeded in $60 \mathrm{~mm}$ tissue culture dishes after the treatments. The seeding density was determined through preliminary experiments where at least 50 colonies formed at the end of the growth period. In the case of the MDAMB-231, cells were grown in culture for a period of 10-14 days. Once the colonies were formed, methylene blue ( $0.1 \%$ in $70 \%$ ethyl alcohol) was used to stain them for counting. The survival fractions of treated cells were determined using the ratio of the number of colonies formed/number of cells seeded $\times$ plating efficiency. More details of clonogenic assay and calculation of survival fraction are shown in Additional file 1: Section S1.

\section{Immunofluorescence assay}

Cells were grown in coverslips (\#1.5 $18 \mathrm{~mm}$ ) in 6-well dishes. After the overnight treatment under different experimental conditions, the cells were rinsed three times with PBS. The cells were then treated with $2 \%$ paraformaldehyde/PBS/0.2\% and Triton X-100 for $20 \mathrm{~min}$ followed by treatment with $0.5 \%$ NP40 for $20 \mathrm{~min}$. Cover slips were left in $2 \%$ BSA/1\% donkey serum in PBS for $1 \mathrm{~h}$. Cells were washed with PBS three times for 5 min between each treatment. Following this, the coverslips were fixed with a primary antibody (53BP1 Ser 1778. 1:200; Cell Signalling Technologies) overnight. The coverslips were then washed with $0.5 \%$ BSA/0.175\% Tween 20/PBS (secondary wash) for 5 min three times before being treated with an optically labeled secondary antibody (antirabbit IgG Alexa 488. 1:500; Life Technologies) for $45 \mathrm{~min}$. The coverslips were washed with the secondary wash before being treated with $0.1 \mu \mathrm{g} / \mathrm{mL}$ of DAPI for $10 \mathrm{~min}$. The coverslips were then finally washed with PBS for 5 min three times and mounted onto glass slides after adding a drop of antifade solution. The edges were sealed and stored at $4{ }^{\circ} \mathrm{C}$ in the dark. The slides were then imaged with a LSM 700 confocal microscope (Carl Zeiss Microscopy, Jena, Germany) and analyzed with the Imaris software (Bitplane, Zurich, Switzerland).

\section{Radiation treatment with linear accelerator}

The cells were grown in 6-well tissue culture dishes and incubated with GNP constructs $16 \mathrm{~h}$ prior to irradiation with a 2 Gy single fraction of $6 \mathrm{MV}$ X-rays with an Agility ${ }^{\mathrm{TM}}$ Linac (Elekta Oncology Systems, Stockholm, Sweden) at a dose rate of $600 \mathrm{MU} / \mathrm{min}$ and field size of $20 \times 20 \mathrm{~cm}^{2}$. The sequence of chemoradiation treatment and the setup used for the study is shown in Additional file 1: Section S2.

\section{Statistical analysis}

Data for clonogenic assays are displayed as mean \pm standard error with at least three repeats. Statistical analyses were performed using the IBM SPSS Statistics (IBM Corporation, New York, USA). A two-sample $t$-test was used to measure statistical significance between pairs of results. For statistical analysis among three or more groups, one-way analysis of variance (ANOVA) was used and subsequent multiple comparisons with 
Bonferroni correction that was performed in any statistical significance was detected by the ANOVA $F$-test. A $p$ value of less than 0.05 was considered to be significant.

\section{Results and discussion}

\section{Cellular accumulation of NPs modified with peptide containing integrin-binding domain, RGD}

TEM, UV spectroscopy, hyperspectral imaging, dynamic light scattering (DLS), and zeta potential measurements are used to characterize the GNP constructs as shown in Fig. 1a-c and Additional file 1: Fig. S3. Hyperspectral imaging technique was used to image GNPs and GNPs in cells. The Fig. 1a is a transmission electron microscopy image of $10 \mathrm{~nm}$ GNPs used in this study. Figure $1 \mathrm{~b}$ is a hyperspectral image of $10 \mathrm{~nm}$ GNPs where the bright dot-like structures are GNPs. Reflectance spectra collected from the bright pixels were confirmed to be GNPs as shown in Fig. 1c. UV visible peak wavelength of unmodified GNPs was $517 \mathrm{~nm}$ as shown in Fig. 1d and this is consistent with the wavelength corresponding to $10 \mathrm{~nm}$ diameter GNPs (Jain et al. 2006). UV visible spectra of RGD peptide conjugated GNPs (referred to as GNP-RGD) had a slight red shift from 517 to $519 \mathrm{~nm}$ as shown in Fig. 1d. This shift is predicted to be due to the RGD peptide ( $1700 \mathrm{Da})$ (Haiss et al. 2007; Amendola and Meneghetti 2009). The zeta potential of NPs changed from -18 to $-12 \mathrm{meV}$ due to the positive charge of the RGD peptide as shown in Additional file 1: Fig. S3.

As shown in Fig. 1e, the cellular accumulation of GNP-RGD was compared with the cellular accumulation of unmodified GNPs. There was a six- to sevenfold increase in cellular accumulation for the GNP-RGDs. The increase in accumulation was visible in qualitative optical images obtained using hyperspectral imaging Fig. 1f, g. The bright dot-like structures were GNP clusters localized within cells. Reflectance spectra were collected from some of those bright spots and it was confirmed that they correspond to GNP clusters localized within cells as shown in Additional file 1: Fig. S4. Improved cellular accumulation of RGD peptide modified GNPs was observed by other research groups as well (Naik et al. 2012; Xu et al. 2012; Zhang et al. 2010, 2011). This integrin-binding domain, RGD, is one of the principle adhesive ligand that can recognizes several integrin families on cell membrane (Ruoslahti and Pierschbacher 1987; Wang et al. 2013). Hence, the significant increase on six- to sevenfold in accumulation for RGD modified GNPs can be predicted to be due to enhanced coupling of GNP complexes with cell surface receptors. The accumulation of GNP constructs is known to be cell line dependent. For example, Bajaj et al. (2009) exposed various types of cells with NP-fluorophore polymer complexes in which they are expected to interact with the cell surface through both electrostatic and hydrophobic interactions. The group measured fluorescence intensities of the various cell types that were exposed to the NP complexes, since the NP-cell interaction was expected to cause a displacement of the fluorophore polymers and generate a fluorescence response (Bajaj et al. 2009). A higher change in fluorescence intensities was observed for MDA-MB-231 (metastatic breast cancer cell line) and MCF-7 (cancerous but non-metastatic breast cancer cell line) than the MCF-10A (normal breast cell line) (Bajaj et al. 2009). Gal et al. (2015) also reported differences in internalization of 200$\mathrm{nm}$ diameter particles in three types of breast cell lines. Accumulation of NPs was significantly higher in MDA-MB-231 (high metastatic potential) and MDA-MB-468 cells 


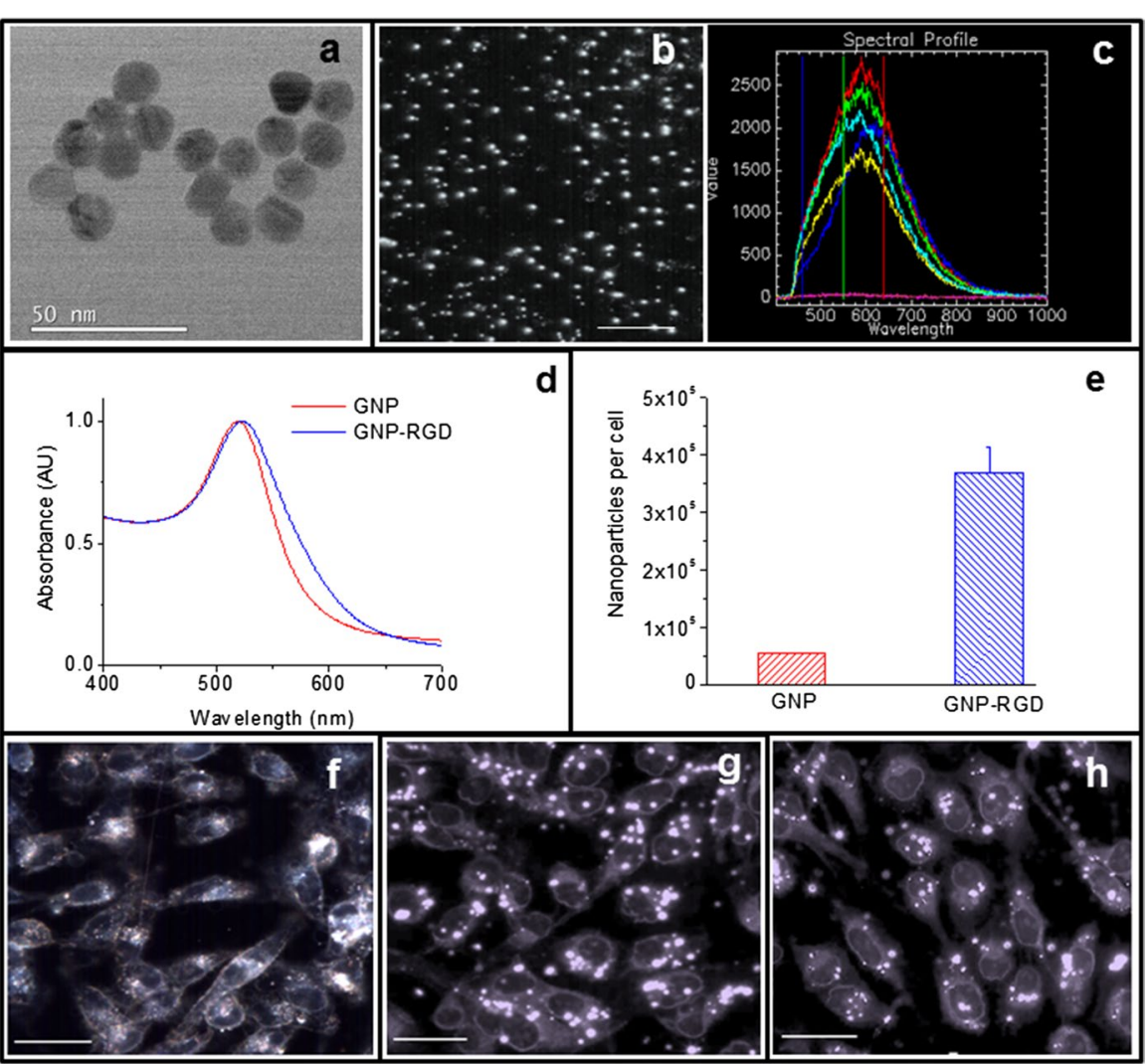

Fig. 1 Characterization and cellular accumulation of GNPs. a Transmission electron microscopy (TEM) image of GNPs used in this study. $\mathbf{b}$ Hyperspectral image of $10 \mathrm{~nm}$ diameter GNPs. Scale bar $=10 \mu \mathrm{m}$. c Reflectance spectra collected from few GNP clusters in the image (b). d UV-Vis Spectra of GNPs and GNP-RGDs measured $46 \mathrm{~h}$ post formulation. e Cellular accumulation of GNPs and GNP-RGDs in MDA-MB-231 cells. Data are mean \pm S.D. for $n=3$. *Represents statistically significant difference (unpaired $t$-test, $p<0.05$ ). f, $\mathbf{g}$ Hyperspectral images of cells internalized with GNPs and GNP-RGDs, respectively. The bright dot-like structures are GNP clusters localized within cells. Scale bar $=10 \mu \mathrm{m}$

(low metastatic potential) compared to MCF-10A cells (benign). This group suggested that the difference in accumulation is because normal cells form tight intra-connected colonies and therefore, NPs can be internalized mostly only at the edge of a growing colony, while in malignant cells, the cell-cell and the cell-matrix connection is disturbed and therefore, NPs can be internalized into any cell on the tissue culture plate (Gal et al. 2015).

\section{Radiation therapy using RGD peptide modified GNPs}

To study the radiation dose enhancement due to GNPs, clonogenic assays and immunofluorescence assays were used. As shown in Fig. 2a, the cells incubated with GNP-RGDs prior to the radiation had a $19 \pm 6 \%$ decrease in cell survival fraction compared to the control cells (with no GNPs). This significant decrease in cell survival fraction could be due to the six- to sevenfold increase in GNP accumulation with the surface modification. The incubation concentration of GNPs was $0.3 \mathrm{nM}$ and it is relatively lower than the incubation concentration used in previously published studies where either $\mu \mathrm{M}$ or $\mathrm{mM}$ GNPs concentration were used (Jain et al. 2011; Wang et al. 2013, 2015; Geng et al. 2011; 
Liu et al. 2008; Haume 2016). Enhancement in cell killing in the presence of GNPs during a radiation treatment is due to the production of larger number of free radicals that can damage DNA lowering their survival (Carter et al. 2007).

DNA damage was probed from immunofluorescence assays and demonstrated both quantitatively and qualitatively as shown in Fig. 2b, c. The nuclei were stained with DAPI (4',6-diamidino-2-phenylindole, dihydrochloride), and 53BP1 proteins were tagged with Alexa 488 which is shown in green in Fig. 2c. The slides were imaged along the $z$-stack to cover the depth of the nuclei. The volume images were produced by 3 -dimensional (3D) reconstruction. The quantitative data was produced by counting the $53 \mathrm{BP} 1$ and divided by the 2D projected area of all the nuclei imaged ( $n=274$ for control, $n=310$ for GNP-RGD). The 53BP1 foci/nuclear area was $0.024 \pm 0.0056$ and $0.026 \pm 0.0059$ for the IR control and IR GNP-RGD cells, respectively, and the difference was small but statistically significant $(p<0.05)$. The cells treated with GNP-RGD prior to the $2 \mathrm{~Gy}, 6 \mathrm{MV}$ radiation had an increase in the 53BP1 count per nuclei area compared to the cells that were treated with saline (irradiated control) prior to radiation as shown in Fig. 2b. One of the important regulators of DSB signaling is p53-binding protein 1 (53BP1). In this study, 53BP1 binding protein was probed to map the DNA DSBs damage. One of the important milestones achieved in this study was to use $10 \mathrm{~nm}$ GNPs at a relatively low incubation concentration $(0.3 \mathrm{nM})$ in combination with clinically relevant higher energy radiation (6 MV) while still causing damage to DNA. The GNP concentration used for this study was $0.3 \mathrm{nM}$, while previously published studies used concentrations between $0.3 \mu \mathrm{M}$ and $1 \mathrm{mM}$ (Haume 2016).

\section{Drug delivery using gold nanoparticles}

After modifying the GNP-RGD complex with BLM, the accumulation of GNP-RGDBLM complexes in cells did not differ from the accumulation of GNP-RGD complexes as shown in Fig. 3a. Comparison of qualitative optical images in Figs. 1g and 3b further supports the quantitative data in Fig. 3a. Cells treated with GNP-RGD-BLM had an $18 \pm 4 \%$ decrease in tumor cell survival compared to the group that were incubated with the same amount of the free drug, BLM as shown in Fig. 3c. Although the precise mechanism of action of bleomycin is not fully known, it is thought that the primary action is to produce single- and double-strand breaks in DNA, via a deoxyribose oxidation step that is similar to the free radical damage produced by GNPs in the presence of radiation. To establish a dose enhancement factor (DEF), the survival fraction of MDA MB 231 cells treated with various concentrations of bleomycin $(0.25-2$ times of $633 \mathrm{nM}-$ the concentration used throughout the experiment) were plotted with a linear trend line of $y=-0.5806 x+1.1608, R^{2}=0.9729$ as shown in Fig. $3 \mathrm{~d}$. The survival fraction (SF) of cells incubated with GNP-RGD-BLM was 0.40. This SF was compared against this trend line and the DEF was calculated to be 1.31 .

Jain et al. (2011) also studied the variation in cell survival fraction with free BLM and combination of BLM with GNPs, where $12 \mu \mathrm{M}$ GNPs were first exposed to cells prior to the treatment with micro-molar concentrations of BLM. Results from this paper demonstrate that the conjugation of anticancer drugs onto GNPs would facilitate effective delivery of anticancer drugs at low concentrations. 


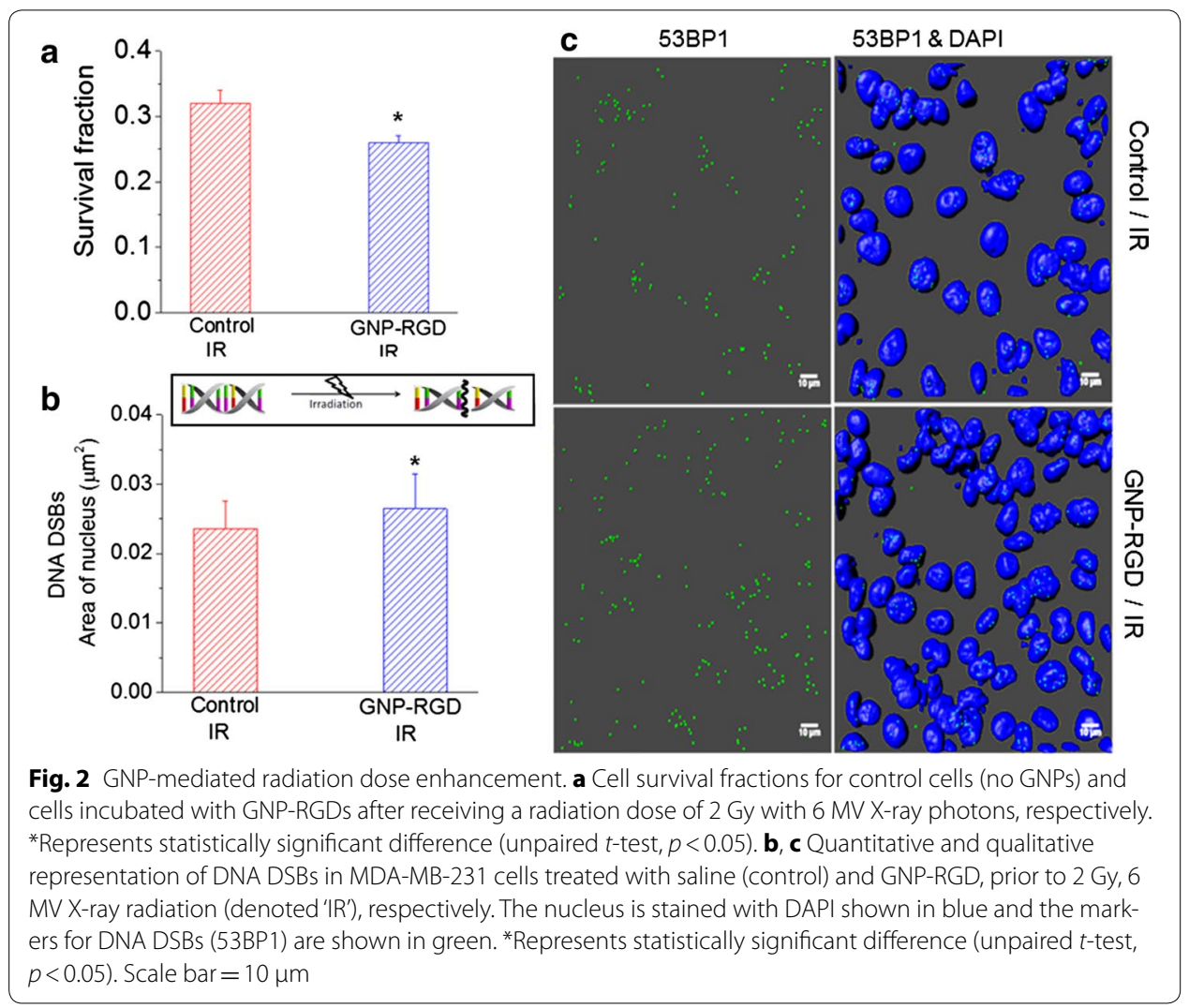

\section{GNP-mediated combined therapy}

The next approach was to test the GNP constructs in combined use of radiation therapy and chemotherapy. The integration of chemotherapy with radiation therapy has greatly improved the outcome in cancer treatment (Herscher et al. 1999; Rubin and Carter 1976). The standard treatment protocol is to inject chemotherapeutic drugs to the patients prior to the radiation treatment (Rubin and Carter 1976). For this study, the cells were first treated with drug-conjugated GNPs (GNP-RGD-BLMs) prior to the radiation treatment. To the authors' knowledge, this is the first time GNP-mediated chemoradiation was tested in an in vitro cell model, where the cells were incubated with a nanomolar concentration of GNPs, and where a $6 \mathrm{MV}$ radiation was used. The cells treated with GNP-RGD-BLM and radiation (referred to as IR GNP-RGD-BLM) had a $32 \pm 9 \%(p<0.05)$ decrease in cell survival compared to the cells treated with free bleomycin and radiation (referred to as IR BLM), with the survival fraction of $0.13 \pm 0.005$ and $0.19 \pm 0.015$, respectively, as shown in Fig. 4a. The combination of GNP-RGD-BLM with radiation had a statistically significant increase in cell death compared to the combination of bleomycin and radiation.

The cells treated with GNP-RGD-BLM and cells treated with BLM followed by radiation were both fluorescently tagged with DAPI and 53BP1 antibodies with Alexa 488 probing DNA DSBs $24 \mathrm{~h}$ post-treatment. The fixed cells were then imaged with a confocal microscope and shown in Fig. 4b, c. The slides were imaged along the $z$-stack to cover the depth of the nuclei. The qualitative images were produced by 3-dimensional (3D) reconstruction of the DAPI stained nucleus (shown in blue in Fig. 4c) and overlaying 

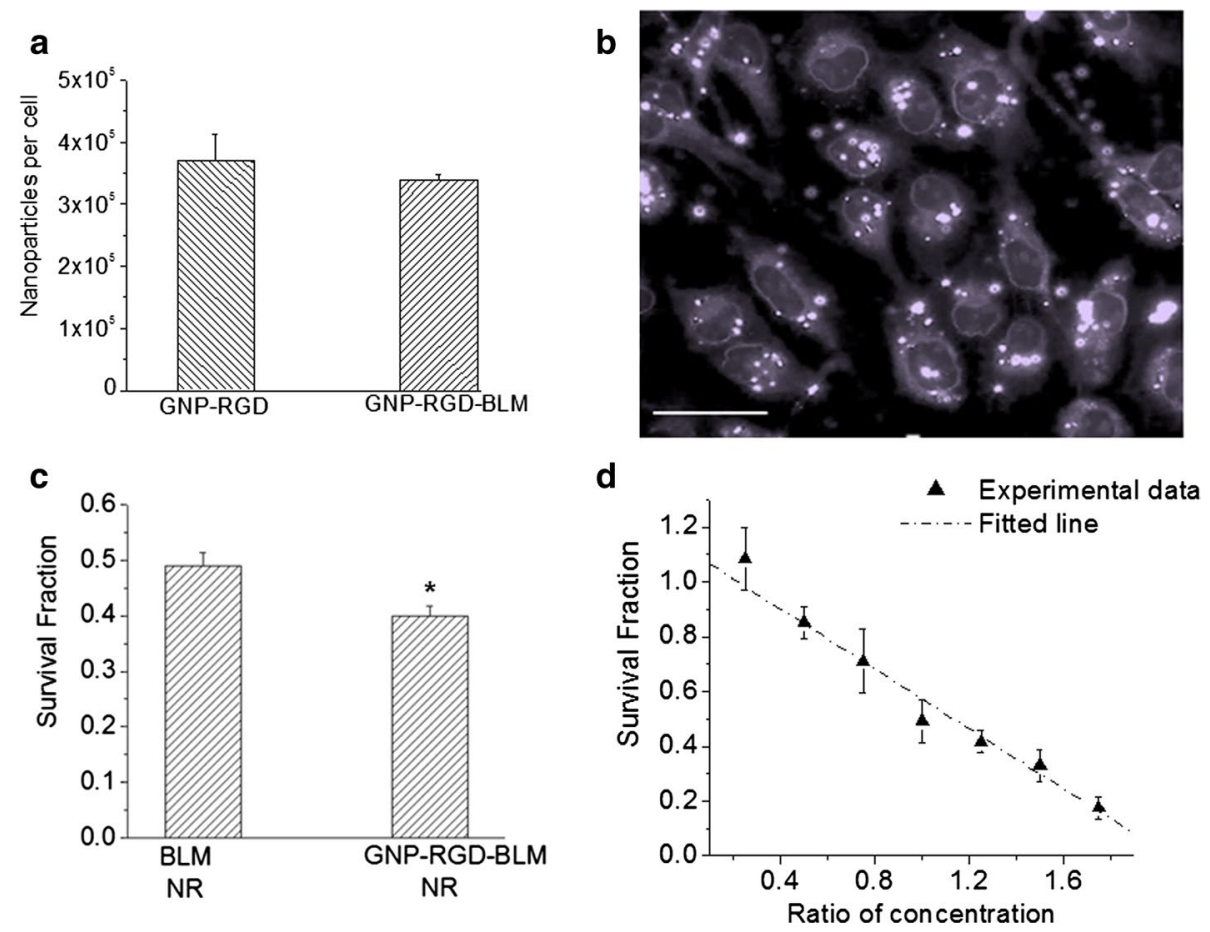

Fig. 3 Cellular accumulation of GNP-drug complex (GNP-RGD-BLM) and the effectiveness of GNP-mediated drug delivery compared to the treatment with free drug (BLM). a Comparison of the cellular accumulation of GNP-RGD compared to GNP-RGD-BLMs. b Hyperspectral image of cells internalized with GNP-RGD-BLMs. The scale bar is $10 \mu \mathrm{m}$. The bright dot-like structures are GNPs localized in cells. c Comparison of cell survival fractions for free BLM and GNP-RGD-BLMs. NR stands for "non-radiated". *Represents statistically significant difference (unpaired $t$-test, $p<0.05$ ). d Variation of cell survival fractions for cells treated with free BLM. Free drug concentrations are presented as a ratio of the free drug and the one used for conjugation with GNPs (633 nM). Data are mean \pm SEM for $n=3$

with the 53BP1 (shown as green pixels in Fig. 4c). The quantitative data was produced by counting the 53BP1 and divided by the 2D projected area of all the nuclei imaged ( $n=389$ for BLM, $n=307$ for GNP-RGD-BLM). The number of 53BP1 foci per 2D projected $z$-stacked nuclear area for cells treated with BLM and GNP-RGD-BLM prior to radiation were $0.032 \pm 0.0043$ and $0.050 \pm 0.0066$, respectively, and the difference was statistically significant $(t$-test, $p<0.05)$. These results indicate that there was an increase in DNA DSBs cells treated with IR GNP-RGD-BLM compared to cells treated with IR BLM. Further therapeutic gains were observed using GNP-RGD-BLM conjugates in combination with radiation. Combination of chemotherapy and radiation therapy is clinically used for cancer treatment and utilizing GNPs as a drug carrier and a radiation sensitizer improves therapeutic outcome of the combinational therapy. The summarized results of radiation therapy, chemotherapy, and combined therapy are shown in Fig. 5ac. Small differences in survival can translate into large differences and therefore a larger significance during a course of multiple treatments. Multiple fractions of radiation are predicted to show an even greater benefit in tumor cell killing, since there is a difference in survival with even one fraction. The effect of presence of GNPs over multiple fractions are calculated in Additional file 1: Table S1. As the next step, the authors will be testing 
a

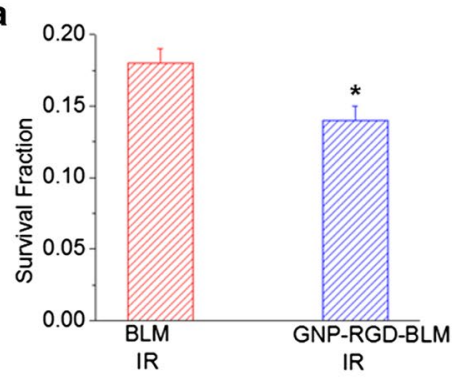

b

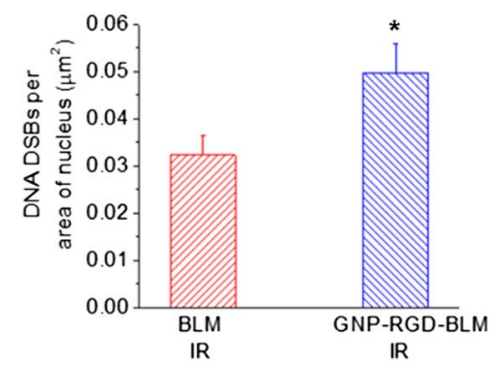

c
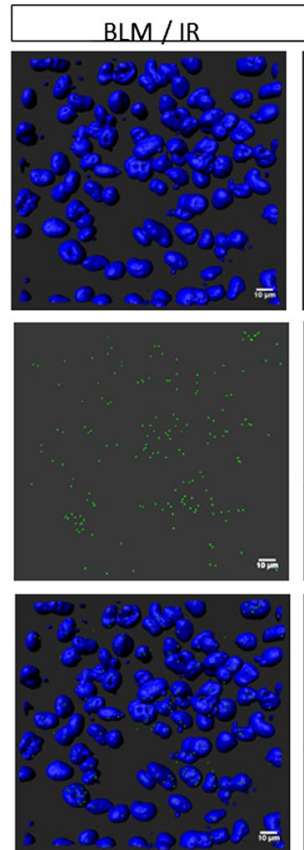

GNP-RGD-BLM / IR
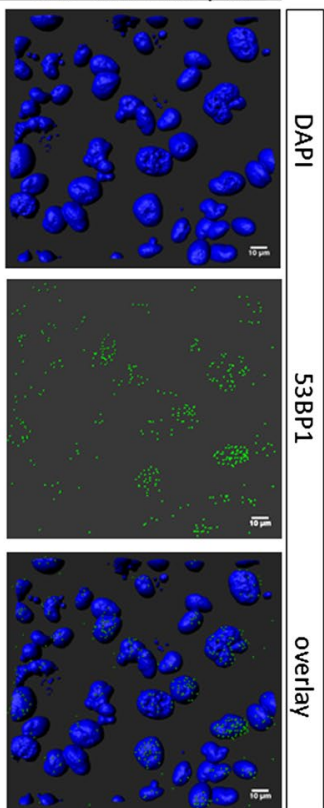

Fig. 4 GNP-mediated chemoradiation. a Comparison of survival fractions cell treated with free BLM compared to cells treated with GNP-RGD-BLM prior to the radiation dose of 2 Gy with 6 MV photons (denoted 'IR'), respectively. *Represents statistically significant difference (unpaired $t$-test, $p<0.05)(\mathbf{b}, \mathbf{c}$ ). Quantitative and qualitative representation of DNA DSBs in MDA-MB-231 cells treated with BLM and GNP-RGD-BLM, prior to $2 \mathrm{~Gy}, 6 \mathrm{MV}$ X-ray radiation (denoted 'IR'), respectively. The nucleus is stained with DAPI shown in blue and the markers for DNA DSBs (53BP1) are shown in green. *Represents statistically significant difference (unpaired t-test, $p<0.05)$. Scale bar $=10 \mu \mathrm{m}$

the construct in different monolayer cell lines, multicellular models, and in vivo studies and will be discussed in future publications.

\section{Toxicity due to GNPs}

Biocompatibility is an important factor for a system to be used in clinical settings and a number of groups studying GNP cytotoxicity concluded that GNP biocompatibility depends on size, surface properties and concentration (Shukla et al. 2005; Connor et al. 2005). Many experimental work has been done to confirm the non-toxicity of GNPs, but contradictory research results are also present (Fratoddi et al. 2015). The lack of general consensus on NP toxicity is due to different experimental methods employed, incubation conditions (concentrations and exposure time), variability of sizes and functionalities of GNPs, variability of cell lines, and different measures and assays for toxicity (Fratoddi et al. 2015; Haume et al. 2016). For example, it has been reported that citrate-capped GNPs were toxic to a human carcinoma lung cell line (A549), but not to a human liver cell line (HepG2) at the same dosage $(120 \mathrm{nM})$ presenting that the toxicity is cell line dependent. The concentration of GNPs used in this study was $0.3 \mathrm{nM}$ and no toxicity effects due to GNPs were observed from clonogenic assays as shown in Additional file 1:

Fig. S5. 


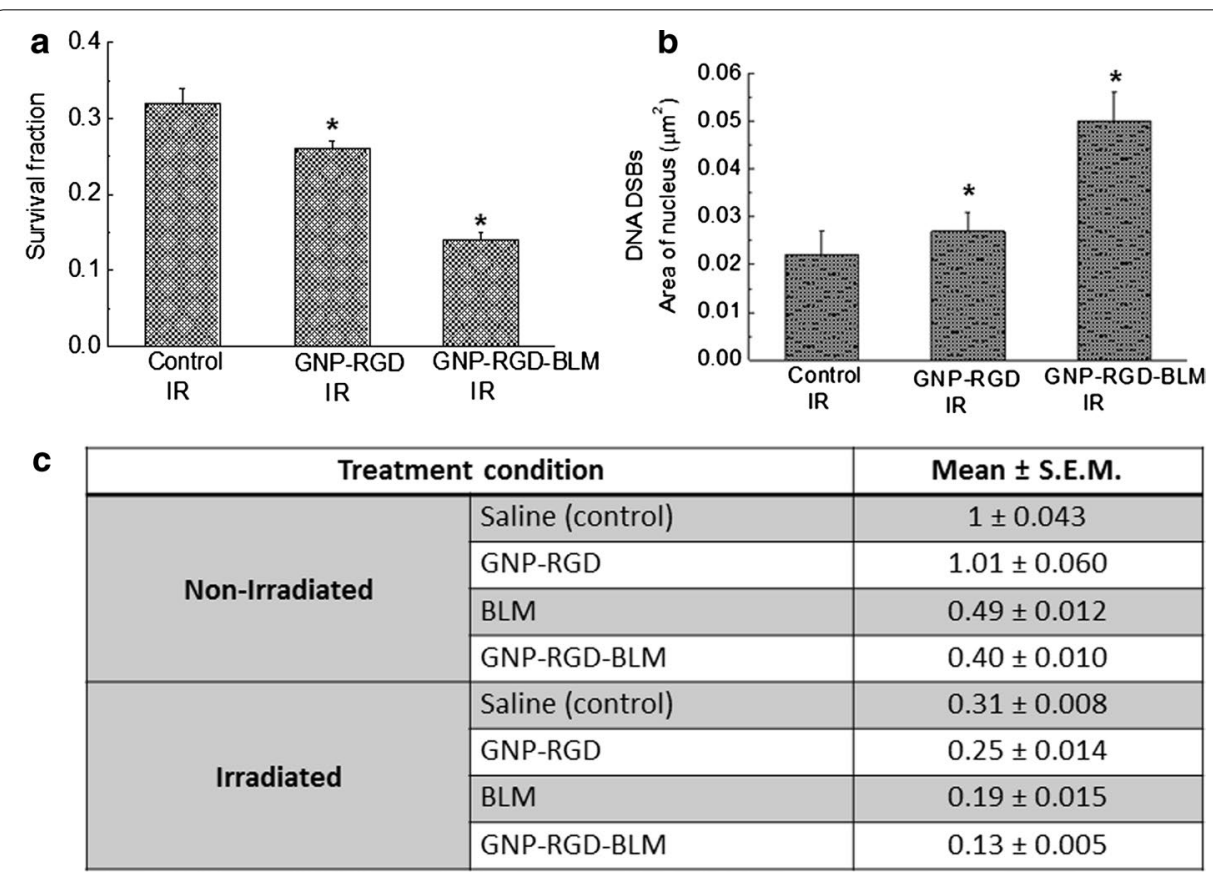

Fig. 5 a, b Comparison of radiation therapy, chemotherapy, and chemoradiation using cell survival fractions and immunofluorescence assay, respectively. ${ }^{*}$ Represents statistically significant difference (unpaired $t$-test, $p<0.05)$. c Summary of clonogenic assay cell survival fractions for all treatment conditions in this study

\section{Conclusions}

The GNP-based platform proposed in this study has the potential for delivering chemotherapeutics more efficiently than free drugs, while at the same time acting as a radiosensitizer as summarized in Fig. 5a-c. Introduction of anticancer drug carrying GNPs into the radiation treatment protocol would give rise to $32 \pm 9 \%$ decrease in tumor cell survival fraction and statistically significant increase in DNA DSBs. Most importantly, the effectiveness of this GNP-mediated chemoradiation was observed at a relatively low $0.3 \mathrm{nM}$ incubation concentration of GNPs. GNPs are also being used in photothermal therapy and photodynamic therapy (Jelveh and Chithrani 2011). Hence, GNP-based multifunctional GNP platform could facilitate the combination of a wide range of therapeutic modalities for delivering a higher therapeutic load to destroy therapeutic resistant tumor cells. With appropriate engineering, these GNP-based platforms have the capacity for controlled delivery of therapeutic doses, while minimizing toxicity to the healthy organs and tissues. It is generally recognized that in vitro data cannot be extrapolated directly to in vivo or clinical settings, since assays in vitro assays do not account for tumour microenvironmental factors and the fact that tumors may contain clonogenic subpopulations of cells with different sensitivities to radiation or chemotherapeutic of interest (Hill and Robert 2008). Further modifications to the GNP-based platform will be performed by the authors and will be tested for in vivo studies.

\section{Additional file}




\section{Abbreviations}

BLM: bleomycin; GNPs: gold nanoparticles; DLS: dynamic light scattering; MV: mega voltage; kV: kilo voltage; ICP-AES: inductively coupled plasma atomic emission spectroscopy; TEM: transmission electron microscopy; HSI: hyperspectral imaging; UV: ultra violet; DSBs: double strand breaks; DMEM: Dulbecco's Modified Eagle's Medium; PBS: phosphate buffered saline; SEM: standard error of mean; ANOVA: analysis of variance.

\section{Authors' contributions}

All authors listed have made substantial, direct, and intellectual contributions to the work discussed in this publication. $B D C$ and $C Y$ designed the article. CY, KB, MP, CDC, GZ performed the experiments analyzed the data, and drafted the paper. All authors discussed the data and revised the manuscript. All authors read and approved the final manuscript.

\section{Author details}

${ }^{1}$ Department of Physics, Ryerson University, 350 Victoria Street, Toronto M5B 2K3, Canada. ${ }^{2}$ Department of Physics and Astronomy, University of Victoria, 3800 Finnerty Road, Victoria M5B 1W8, Canada. ${ }^{3}$ Keenan Research Centre, Li Ka Shing Knowledge Institute, St. Michael's Hospital, 30 Bond Street, Toronto V8P 5C2, Canada. ${ }^{4}$ STTARR Innovation Centre, 101 College Street, MaRS Discovery Tower, Toronto M5G 1L7, Canada. ${ }^{5}$ Department of Radiation Physics, Princess Margaret Cancer Centre, 610 University Avenue, Toronto M5G 2M9, Canada.

\section{Acknowledgements}

The authors would like to acknowledge the Natural Sciences and Engineering Research Council of Canada (NSERC), Canada Foundation for Innovation (CFI) and University of Victoria for their financial support. CY is supported by Ontario Graduate Scholarship in Science and Technology (OGSST).

Competing interests

The authors declare that they have no competing interests.

\section{Availability of data and materials}

Additional material (further details of characterization of GNP complexes, experiential setups used, cell viability data, additional information regarding hyperspectral imaging) is available.

\section{Consent for publication}

Not applicable.

\section{Ethics approval and consent to participate}

Not applicable.

\section{Funding}

We acknowledge the financial support from the Natural Sciences and Engineering Research Council of Canada (NSERC), Canada Foundation for Innovation (CFI), and University of Victoria for their financial support. CY was supported by Ontario Graduate Scholarship in Science and Technology (OGSST).

\section{Publisher's Note}

Springer Nature remains neutral with regard to jurisdictional claims in published maps and institutional affiliations.

Received: 18 December 2017 Accepted: 28 March 2018

Published online: 02 May 2018

\section{References}

Amendola V, Meneghetti M. Size evaluation of gold nanoparticles by uv-vis spectroscopy. J Phys Chem C. 2009;113:4277-85.

Bajaj A, Miranda OR, Kim I-B, Phillips RL, Jerry DJ, Bunz UH, Rotello VM. Detection and differentiation of normal, cancerous, and metastatic cells using nanoparticle-polymer sensor arrays. Proc Natl Acad Sci. 2009;106:10912-6.

Butterworth K, Coulter J, Jain S, Forker J, McMahon S, Schettino G, Prise K, Currell F, Hirst D. Evaluation of cytotoxicity and radiation enhancement using $1.9 \mathrm{~nm}$ gold particles: potential application for cancer therapy. Nanotechnology. 2010;21:295101.

Carter JD, Cheng NN, Qu Y, Suarez GD, Guo T. Nanoscale energy deposition by X-ray absorbing nanostructures. J Phys Chem B. 2007;111:11622-5.

Chithrani BD, Ghazani AA, Chan WC. Determining the size and shape dependence of gold nanoparticle uptake into mammalian cells. Nano Lett. 2006;6:662-8.

Chithrani DB, Jelveh S, Jalali F, van Prooijen M, Allen C, Bristow RG, Hill RP, Jaffray DA. Gold nanoparticles as radiation sensitizers in cancer therapy. Radiat Res. 2010;173:719-28.

Connor EE, Mwamuka J, Gole A, Murphy CJ, Wyatt MD. Gold nanoparticles are taken up by human cells but do not cause acute cytotoxicity. Small. 2005;1:325-7.

Crawford S. Is it time for a new paradigm for systemic cancer treatment? Lesions from a century of cancer chemotherapy. Front Pharmacol. 2013;4:1-18.

Cui L, Tse K, Zahedi P, Harding SM, Zafarana G, Jaffray DA, Bristow RG, Allen C. Hypoxia and cellular localization influence the radiosensitizing effect of gold nanoparticles (AuNPs) in breast cancer cells. Radiat Res. 2014;182:475-88.

Dai X, Cheng H, Bai Z, Li J. Breast cancer cell line classification and its relevance with breast tumor subtyping. J Cancer. 2017:8(16):3131-3141 
Fratoddi I, Venditti I, Cametti C, Russo MV. How toxic are gold nanoparticles? The state-of-the-art. Nano Res. 2015;8:1771-99

Frens G. Controlled nucleation for the particle size in monodisperse gold suspensions. Nature. 1973;241:20-2.

Gal N, Massalha S, Samuelly-Nafta O, Weihs D. Effects of particle uptake, encapsulation, and localization in cancer cells on intracellular applications. Med Eng Phys. 2015;37:478-83.

Gao H, Shi W, Freund LB. Mechanics of receptor-mediated endocytosis. Proc Natl Acad Sci USA. 2005;102:9469-74.

Geng F, Song K, Xing JZ, Yuan C, Yan S, Yang Q, Chen J, Kong B. Thio-glucose bound gold nanoparticles enhance radiocytotoxic targeting of ovarian cancer. Nanotechnology. 2011;22:285101.

Georgelin T, Bombard S, Siaugue JM, Cabuil V. Nanoparticle-mediated delivery of bleomycin. Angew Chem Int Ed. 2010;49:8897-901.

Hainfeld JF, Slatkin DN, Smilowitz HM. The use of gold nanoparticles to enhance radiotherapy in mice. Phys Med Biol. 2004;49:N309.

Hainfeld JF, Slatkin DN, Focella TM, Smilowitz HM. Gold nanoparticles: a new X-ray contrast agent. Br J Radiol. 2006;79:248-53.

Haiss W, Thanh NT, Aveyard J, Fernig DG. Determination of size and concentration of gold nanoparticles from uv-vis spectra. Anal Chem. 2007;79:4215-21.

Haume KEA. Gold nanoparticles for cancer radiotherapy: a review. Cancer Nanotechnol. 2016;7:1-20.

Haume K, Rosa S, Grellet S, Śmiałek MA, Butterworth KT, Solov'yov AV, Prise KM, Golding J, Mason NJ. Gold nanoparticles for cancer radiotherapy: a review. Cancer Nanotechnol. 2016;7:8.

Hecht SM. The chemistry of activated bleomycin. Acc Chem Res. 1986:19:383-91.

Hermanson GT. Preparation of colloidal-gold-labeled proteins, in bioconjugate techniques. New York: Academic press; 1996. p. 593-605.

Herscher LL, Cook JA, Pacelli R, Pass H, Russo A, Mitchell J. Principles of chemoradiation: theoretical and practical considerations. Oncology (Williston Park, NY). 1999;13:11-22.

Hill RPB, Robert B. The scientific basis of radiotherapy. In: Tannock IFH, Richard P, Bristrow RG, Harrington L, editors. The basic science of oncology. Toronto: McGraw-Hill; 2008. p. 289-321.

Jain PK, Lee KS, El-Sayed I, El-Sayed M. Calculated absorption and scattering properties of gold nanoparticles of different size, shape, and composition: applications in biological imaging and biomedicine. J Phys Chem B. 2006;110:7238-48.

Jain S, Coulter JA, Hounsell AR, Butterworth KT, McMahon SJ, Hyland WB, Muir MF, Dickson GR, Prise KM, Currell FJ. Cellspecific radiosensitization by gold nanoparticles at megavoltage radiation energies. Int J Radiat Oncol Biol Phys. 2011;79:531-9.

Jain S, Coulter JA, Butterworth KT, Hounsell AR, McMahon SJ, Hyland WB, Muir MF, Dickson GR, Prise KM, Currell FJ. Gold nanoparticle cellular uptake, toxicity and radio sensitisation in hypoxic conditions. Radiother Oncol. 2014;1 10:342-7.

Jelveh S, Chithrani DB. Gold nanostructures as a platform for combinational therapy in future cancer therapeutics. Cancers. 2011;3:1081-110.

Liu C-J, Wang C-H, Chien C-C, Yang T-Y, Chen S-T, Leng W-H, Lee C-F, Lee K-H, Hwu Y, Lee Y-C. Enhanced X-ray irradiationinduced cancer cell damage by gold nanoparticles treated by a new synthesis method of polyethylene glycol modification. Nanotechnology. 2008;19:295104.

Ma BB, Bristow RG, Kim J, Siu LL. Combined-modality treatment of solid tumors using radiotherapy and molecular targeted agents. J Clin Oncol. 2003;21:2760-76.

McMahon SJ, Hyland WB, Muir MF, Coulter JA, Jain S, Butterworth KT, Schettino G, Dickson GR, Hounsell AR, O'Sullivan JM. Nanodosimetric effects of gold nanoparticles in megavoltage radiation therapy. Radiother Oncol. 2011;100:412-6.

Naik S, Patel D, Chuttani K, Mishra AK, Misra A. In vitro mechanistic study of cell death and in vivo performance evaluation of rgd grafted pegylated docetaxel liposomes in breast cancer. Nanomed Nanotechnol Biol Med. 2012;8:951-62.

Perrault SD, Walkey C, Jennings T, Fischer HC, Chan WC. Mediating tumor targeting efficiency of nanoparticles through design. Nano Lett. 2009;9:1909-15.

Rahman WN, Bishara N, Ackerly T, He CF, Jackson P, Wong C, Davidson R, Geso M. Enhancement of radiation effects by gold nanoparticles for superficial radiation therapy. Nanomed Nanotechnol Biol Med. 2009;5:136-42.

Rubin P, Carter SK. Combination radiation therapy and chemotherapy: a logical basis for their clinical use. CA Cancer J Clin. 1976;26:274-92.

Ruoslahti E, Pierschbacher MD. New perspectives in cell adhesion: Rgd and integrins. Science. 1987;238:491-8.

Shukla R, Bansal V, Chaudhary M, Basu A, Bhonde RR, Sastry M. Biocompatibility of gold nanoparticles and their endocytotic fate inside the cellular compartment: a microscopic overview. Langmuir. 2005;21:10644-54.

Siu LLM, Malcolm J. Pharmacology of anticancer drugs. In: Tannock IFH, Richard P, Bristrow RG, Harrington L, editors. The basic science oncology. Toronto: McGraw-Hill; 2005. p. 322-48.

Stewart BWKP, Wild CP. World cancer report. 2014.

Umezawa Y, Morishima H, Saito S, Takita T, Umezawa H, Kobayashi S, Otsuka M, Narita M, Ohno M. Synthesis of the pyrimidine moiety of bleomycin. J Am Chem Soc. 1980;102:6630-1.

Vloedgraven H, Papapoulos S, Löwick C, Grzesik W, Kerr J, Robey P. Attachment characteristics and involvement of integrins in adhesion of breast cancer cell lines to extracellular bone matrix components. Lab Invest. 1997;77:665-75.

Wang F, Li Y, Shen Y, Wang A, Wang S, Xie T. The functions and applications of rgd in tumor therapy and tissue engineering. Int J Mol Sci. 2013a;14:13447-62.

Wang C, Li X, Wang Y, Liu Z, Fu L, Hu L. Enhancement of radiation effect and increase of apoptosis in lung cancer cells by thio-glucose-bound gold nanoparticles at megavoltage radiation energies. J Nanopart Res. 2013b;15:1642.

Wang C, Jiang Y, Li X, Hu L. Thioglucose-bound gold nanoparticles increase the radiosensitivity of a triple-negative breast cancer cell line (mda-mb-231). Breast Cancer. 2015;22:413-20.

Xu Q, Liu Y, Su S, Li W, Chen C, Wu Y. Anti-tumor activity of paclitaxel through dual-targeting carrier of cyclic rgd and transferrin conjugated hyperbranched copolymer nanoparticles. Biomaterials. 2012;33:1627-39.

Yang C, Uertz J, Yohan D, Chithrani B. Peptide modified gold nanoparticles for improved cellular uptake, nuclear transport, and intracellular retention. Nanoscale. 2014;6:12026-33. 
Yang C, Uertz J, Chithrani DB. Colloidal gold-mediated delivery of bleomycin for improved outcome in chemotherapy. Nanomaterials. 2016:6:48.

Yohan D, Chithrani BD. Applications of nanoparticles in nanomedicine. J Biomed Nanotechnol. 2014;10:2371-92.

Yohan D, Cruje C, Lu X, Chithrani D. Elucidating the uptake and distribution of nanoparticles in solid tumors via a multilayered cell culture model. Nano-Micro Lett. 2015;7:127-37.

Zhang Y-F, Wang J-C, Bian D-Y, Zhang X, Zhang Q. Targeted delivery of rgd-modified liposomes encapsulating both combretastatin a-4 and doxorubicin for tumor therapy: in vitro and in vivo studies. Eur J Pharm Biopharm. 2010;74:467-73.

Zhang L, Zhu S, Qian L, Pei Y, Qiu Y, Jiang Y. Rgd-modified peg-pamam-dox conjugates: in vitro and in vivo studies for glioma. Eur J Pharm Biopharm. 2011;79:232-40.

Submit your manuscript to a SpringerOpen ${ }^{\circ}$ journal and benefit from:

- Convenient online submission

- Rigorous peer review

- Open access: articles freely available online

- High visibility within the field

- Retaining the copyright to your article

Submit your next manuscript at $\boldsymbol{s p r i n g e r o p e n . c o m ~}$ 